\title{
Vem Fazer Química Online! - A Página Web do Grupo de Químicos Jovens -
}

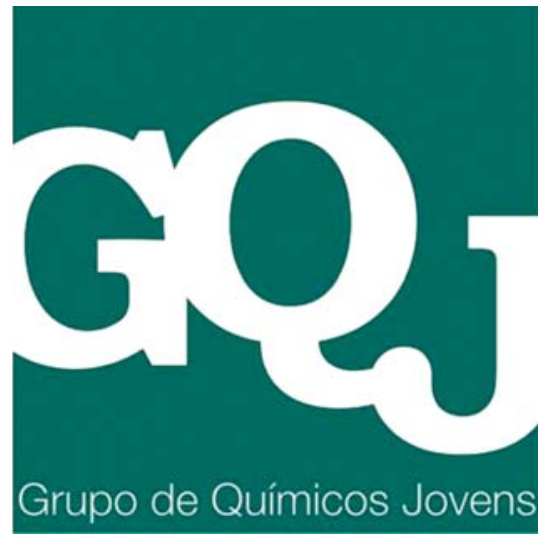

No último número do Boletim apresentámos de uma forma geral os conteúdos da nova página Web do Grupo de Químicos Jovens (GQJ): http://www.spq.pt/gqj/. No presente número, apresentamos de uma forma mais detalhada as secções ChemЯUs, JobChem e CheMba que consideramos de importância estratégica para o futuro do GQJ.

ChemяUs - este espaço foi criado com o objectivo de se tornar uma biblioteca de experiências de Química composta pela respectiva ficha pedagógica/científica e por um vídeo demonstrativo. Com esta iniciativa, pretendemos que a Química possa ser vista como uma disciplina divertida, responsável e de vital importância para a Sociedade. Para que esta biblioteca possa ser constituída, contamos com a participação da comunidade científica universitária, com os professores de química do ensino básico e secundário e muito em especial com os seus jovens alunos que são o futuro da Química em Portugal.

Nesta fase inicial, estão disponíveis experiências desenvolvidas por alguns jovens cientistas colaboradores do GQJ. No entanto, o ChemЯUs é um espaço aberto a toda a comunidade química portuguesa, e espera-se a contribuição de todos para o aumento do portfolio de experiências. Contamos com o entusiasmo de muitos jovens estudantes do ensino básico e secundário e respectivos professores, para que desenvolvam experiências químicas e as disponibilizem para que mais químicos possam aprender Química de uma forma entusiasta e interactiva.

Todas as experiências serão acompanhadas por uma ficha que poderá incluir a seguinte informação: introdução com perspectiva histórica; procedimento experimental detalhado com atenção às questões da segurança; breve discussão de mecanismos e fenómeno em estudo; possíveis aplicações da reacção, produtos ou materiais; conclusões e perguntas relativas aos conceitos subjacentes à experiência. Os critérios de escolha para a realização das experiências são: a segurança, o custo da experiência, a relevância dos conceitos para o estudo da química, a espectacularidade visual, etc. As fichas devem ser enviadas para gqj@spq.pt, e posteriormente será acordada a forma de disponibilizar o vídeo.

JobChem - este espaço pretende auxiliar os jovens químicos (JQ) a encontrar emprego científico. Assim esta secção está dividida em duas componentes:

1) Compilações de motores de busca com sites de oferta de emprego. Estes podem ser acedidos através dos links na barra lateral "Pesquisas Nacionais" e "Pesquisas Internacionais" com um simples click no seu título. É facultada uma breve descrição de cada motor de busca sugerido de forma a facilitar a sua utilização. Esta seleção inicial poderá ser enriquecida ou revista de acordo com os comentários dos utilizadores para jobchem.gqj@ spq.pt.

2) A segunda componente deste site é constituida por um espaço onde entidades públicas e privadas poderão colocar directamente as suas ofertas de bolsas e empregos. Convidamos assim os diferentes responsáveis por projectos de investigação financiados com bolsas associadas e que estejam interessados em divulgar o con- curso das mesmas, que façam o download da ficha que se encontra na página do GQJ e a enviem devidamente preenchida para jobchem.gqj@spq.pt. O mesmo convite é feito aos diversos gabinetes de estágios e recursos humanos de universidades e empresas privadas para que utilizem esta plataforma para divulgar os lugares disponíveis nas suas organizações.

Comentários, sugestões e participação nesta iniciativa podem ser encaminhadas via email para:

jobchem.gqj@spq.pt ao cuidado de João Pedro Nunes, o jovem químico responsável por esta área do GQJ.

CheMba - este espaço surge com a intenção de guiar os JQ nos seus primeiros passos rumo ao empreendorismo. Esta secção é composta por duas componentes:

1) A primeira é essencialmente informativa, uma vez que na barra lateral da secção, os utilizadores poderão encontrar informação actualizada sobre as principais instituições associadas ao empreendorismo. Os JQ interessados em empreendorismo podem ainda encontrar nesta secção informação relativa a programas de apoios à criação de empresas, a potenciais fontes de financiamento, a programas de formação em empreendorismo, e a prémios a que o JQ poderá concorrer.

2) A segunda componente desta secção visa facilitar a interacção directa entre JQ e profissionais com formação em gestão. Assim, é dada a possibilidade de agendar reuniões entre os profissionais com formação em gestão e os $J Q$, onde estes últimos poderão discutir, estruturar e ponderar os desafios associados à empresarialização da sua ideia. Neste momento o CheMba conta já com cinco ex-alunos de MBA disponíveis para arrancar com esta iniciativa. O código de conduta CheMba, que descreve o âmbito e processo 
desta iniciativa, está disponível na página do GQJ.

Comentários, sugestões e participação nesta iniciativa podem ser encaminhadas via email para:

chemba.gqj@spq.pt ao cuidado de Pedro Vidinha e Nuno Lourenço, os jovens químicos empreendedores responsáveis por esta área do GQJ.
Mais uma vez apelamos para a adesão dos jovens químicos (< 35 anos) ao GQJ.

Para oficializares a tua adesão ao GQJ basta enviares um fax (+351 217952349) ou email (sede@spq.pt) indicando o teu nome, $\mathrm{n}^{\circ}$ de sócio da SPQ e a intenção de pertenceres ao GQJ. Só com a ajuda de todos o GQJ se tornará um espaço incontornável na divulgação e celebração da Química por jovens em Portugal.

Contamos com a tua visita e participação!

Grupo de Químicos Jovens Carlos Baleizão, Frederico Ferreira, Pedro Gois

\section{Actualidade Científica}

\section{ÁcIDO SULFÚRICO}

O ácido sulfúrico é uma substância de elevada viscosidade, cujo aspecto oleoso Ihe mereceu o nome Zayt al-Zaj, óleo de vitriol, por parte do seu mais provável descobridor, o pai da alquimia árabe, Jābir ibn Hayyān ou Geber. Jābir ou Geber escreveu tratados de filosofia, astronomia, medicina e biologia, mas a sua maior contribuição verificou-se no campo da alquimia. Introduziu a investigação experimental na alquimia, lançando as bases para a química moderna, ao realçar que « $A$ coisa primordial na alquimia é que se pode realizar trabalhos práticos e conduzir experiências», acrescentando que «quem não faz trabalhos práticos nem faz experiências nunca dominará a alquimia».

Alguns autores atribuem a descoberta do ácido sulfúrico a outro árabe do século VIII, Abu Bakr Muhammad ibn Zakaryya al-Razi, Rahzes em latim, nascido na cidade de Ray ou Rhagae. al-Razi escreveu 21 livros de alquimia, dos quais o mais conhecido é o Kitab Sirr al-Asrar (Livro do Segredo dos Segredos) onde o filósofo discorre sobre os equipamentos e as substâncias utilizadas na alquimia. Outro dos seus tratados de alquimia, traduzido para latim como Liber Experimentorum, marcava claramente o aspecto experimental da alquimia, despindo-a da componente mística característica da escola de Alexandria.

Este ácido inorgânico, descoberto por um alquimista no século VIII, é actualmente o produto químico mais produzido no mundo (em termos de massa, em número de moléculas perde para a amónia). Praticamente todos os produtos manufacturados entraram em contacto com $\mathrm{H}_{2} \mathrm{SO}_{4}$ em algum estágio da sua produção a tal ponto que até há bem pouco tempo o grau de industrialização de um país era medido pela produção anual de ácido sulfúrico.

Hoje em dia, a principal utilização de ácido sulfúrico é a produção de fertilizantes, dado que foi progressivamente substituído na produção de aço por outro ácido mineral descoberto por Geber, o ácido clorídrico. A produção de ácido sulfúrico passou a ser uma medida da actividade agrícola de um país.

Até ao século XVII, quando Johann Glauber preparou ácido sulfúrico queimando enxofre com salitre (nitrato de potássio, $\mathrm{KNO}_{3}$ ) na presença de vapor de água, a produção de ácido sulfúrico permaneceu a preconizada pelos alquimistas árabes: a «destilação» seca de sulfatos sortidos, nomeadamente vitríolo verde ou sulfato ferroso $\left(\mathrm{FeSO}_{4} \cdot 7 \mathrm{H}_{2} \mathrm{O}\right)$ e vitríolo azul ou sulfato de cobre $\left(\mathrm{CuSO}_{4} \cdot 5 \mathrm{H}_{2} \mathrm{O}\right)$.

A síntese de Glauber, aperfeiçoada por vários químicos, entre eles Gay-Lussac, foi utilizada até ao século XIX. Em 1831, um comerciante britânico de vinagre, Peregrine Phillips, patenteou um processo novo de produção de ácido sulfúrico que, embora só tenha sido extensivamente utilizado a partir de finais do século XIX, dominou a produção deste composto a partir de meados do século XX. Actualmente, o ácido sulfúrico é essencialmente pro- duzido de forma «verde», isto é, recuperando sub-produtos e resíduos de indústrias outrora muito poluentes.

Como nota de curiosidade, refira-se que algumas lesmas do mar produzem ácido sulfúrico para afastar possíveis predadores. De facto, os nudibrânquios - literalmente, guelras ou brânquias nuas -, presentes em todos os oceanos e em praticamente todos os habitats marinhos, são especialistas em guerra química, recorrendo a um vasto arsenal de compostos como defesa contra predadores esfomeados. Enquanto algumas espécies produzem ácidos, outras segregam toxinas poderosas e outras ainda, os eolídeos, utilizam as armas químicas das espécies que lhes servem de alimento.

Palmira Silva 